\title{
Management of recurrent malignant pleural effusion in the United Kingdom: survey of clinical practice
}

\author{
Lawrence G McAlpine, Geoffrey Hulks, Neil C Thomson
}

\begin{abstract}
Malignant pleural effusions are often symptomatic and tend to recur after simple aspiration. Pleurodesis may prevent recurrence of the effusion; many agents and techniques have been described. A questionnaire was sent to 448 clinicians in the United Kingdom to determine how pleurodesis is performed in practice. There was a $56 \%$ overall response, with replies from 101 respiratory physicians, 88 general physicians, 29 thoracic surgeons, and 35 general surgeons. General surgeons saw few cases of malignant pleural effusion and rarely performed pleurodesis. A patient with recurrent malignant pleural effusion would usually be managed with pleurodesis by $76(76 \%)$ respiratory physicians, $26(30 \%)$ general physicians, and $23(81 \%)$ thoracic surgeons; a further $29(33 \%)$ general physicians would refer such patients to another specialist. Most medical pleurodeses were performed by junior staff, whereas consultant thoracic surgeons were more likely to be concerned with the procedure. All the thoracic surgeons used an intercostal tube drain, usually with suction. An intercostal tube drain was used routinely by only $54(54 \%)$ of the respiratory physicians and 28 (32\%) general physicians. Thoracic surgeons preferred talc for pleurodesis whereas physicians most commonly used tetracycline. The variety of methods in use supports the need for randomised, controlled studies to determine the most effective technique of pleurodesis.
\end{abstract}

Malignant disease is a common cause of pleural effusion..$^{1-3}$ These effusions are often large and associated with breathlessness and chest discomfort. Recurrence of the effusion after simple aspiration is almost invariable. ${ }^{14}$ Patients who are not in the terminal phase of their illness may require repeated aspiration to relieve symptoms unless an attempt is made to prevent the recurrence of the effusion. Pleurodesis may be effective in achieving this aim by obliterating the pleural space.

Various methods of pleurodesis are described in textbooks ${ }^{56}$ and articles ${ }^{78}$ and many agents have been subjected to trial. Advice on the performance of this technique remains confused, however, and the approach of clin- icians to the problem is not known. We present the results of a survey designed to determine how patients with recurrent malignant pleural effusion are managed and which methods of pleurodesis are used by clinicians in the United Kingdom.

\section{Methods}

A questionnaire was sent to the following groups of consultants who might be expected to see patients with malignant pleural effusion: physicians with an interest in respiratory medicine $(\mathrm{n}=150)$; general physicians and physicians with a non-respiratory interest $(n=173)$; thoracic surgeons $(\mathrm{n}=48)$; and general surgeons $(\mathrm{n}=77)$. The names of the respiratory physicians were taken randomly from a list produced by the British Thoracic Society ${ }^{9}$ and the names of the other consultants were obtained from the Medical Directory. ${ }^{10}$ An individually addressed and signed covering letter and a stamped, addressed reply envelope accompanied each questionnaire to encourage response.

The questionnaire was anonymous. It requested the respondent to identify his or her specialty and to estimate the number of patients with malignant pleural effusion seen each year. Replies from those seeing fewer than two cases of malignant pleural effusion a year were excluded from further analysis. It then asked whether the usual practice in dealing with recurrent malignant pleural effusion was repeated aspiration, pleurodesis, or referral to another specialist. Replies from those who do not perform pleurodesis (that is, aspirate only, or refer elsewhere) were not analysed further. Those who undertook pleurodesis were asked questions on the method and the agent used in the procedure.

\section{Results}

Replies were received from $101(67 \%)$ respiratory physicians, $88 \quad(50 \%)$ general physicians, $29(60 \%)$ thoracic surgeons, and $35(45 \%)$ general surgeons; there were therefore 253 replies, giving an overall response rate of $56 \%$.

GENERAL SURGEONS

Seventeen of the 35 replies from general surgeons estimated that they saw fewer than two cases of malignant pleural effusion a year; of the remainder, two referred such patients to another specialist. The remaining 16 replies 
Table 1 Estimated annual numbers of cases of malignant pleural effusion seen by respiratory physicians, general physicians, and thoracic surgeons

\begin{tabular}{llll}
\hline No of cases & $\begin{array}{l}\text { Respiratory } \\
\text { physicians } \\
(n=101) \\
\text { No(\%) }\end{array}$ & $\begin{array}{l}\text { General } \\
\text { physicians } \\
(n=88) \\
\text { cases } / y\end{array}$ & $\begin{array}{l}\text { Thoracic } \\
\text { surgeons } \\
(n=29) \\
\text { No }(\%)\end{array}$ \\
\hline 0 & 0 & $4(5)$ & 0 \\
$0-2$ & 0 & $24(27)$ & 0 \\
$2-4$ & 0 & $35(40)$ & $5(17)$ \\
$5-10$ & $34(34)$ & $21(24)$ & $8(28)$ \\
$>10$ & $66(66)$ & $4(5)$ & $14(48)$ \\
\hline
\end{tabular}

were evenly divided, eight managing such patients by repeated thoracocentesis as required and eight considering pleurodesis. Analysis of responses to questions on the technique of pleurodesis was not performed in view of the small sample size.

RESPIRATORY PHYSICIANS, GENERAL

PHYSICIANS, THORACIC SURGEONS

Number of patients with malignant pleural effusion seen each year

All respiratory physicians estimated that they saw five or more patients with malignant pleural effusion each year, whereas only 25 $\left(29_{0}^{\circ}\right)$ general physicians saw this number (table 1).

\section{Management approach to recurrent malignant} pleural effusion

Pleurodesis would usually be considered by $76(76 \%)$ respiratory physicians in a patient with recurrent malignant pleural effusion; $2 \%$ would manage these patients with aspiration alone and $18 \%$ have a variable approach. Only $26\left(30^{\circ}\right)$ general physicians would consider performing pleurodesis and a further 29 $\left(33^{\circ}{ }_{0}\right)$ would refer such patients to another specialist for management; $13(15 \%)$ would perform aspiration alone and $16(18 \%)$ would vary their approach. Most thoracic surgeons $(23,81 \%$ ) would perform pleurodesis; only one respondent said he would only aspirate; the remainder had a variable approach.

Sixty eight $(68 \%)$ respiratory physicians delegated the task of pleurodesis to a junior member of staff; $5 \%$ performed the procedure themselves and $24 \%$ sometimes performed the procedure themselves. Only six $(7 \%)$ general physicians ever attempted the procedure personally, the remainder delegating to junior

Table 2 Method of drainage of pleural fluid at pleurodesis by respiratory physicians, general physicians, and thoracic surgeons

\begin{tabular}{llll}
\hline & $\begin{array}{l}\text { Respiratory } \\
\text { physicians } \\
(n=96) \\
\text { No }(\%)\end{array}$ & $\begin{array}{l}\text { General } \\
\text { physicians } \\
(n=28) \\
\text { No }(\%)\end{array}$ & $\begin{array}{l}\text { Thoracic } \\
\text { surgeons } \\
(n=26) \\
\text { No }(\%)\end{array}$ \\
\hline $\begin{array}{l}\text { Needle aspiration } \\
\text { Intercostal drain }\end{array}$ & $11(11)$ & $11(39)$ & 0 \\
$\begin{array}{l}\text { Drain with or } \\
\text { without suction }\end{array}$ & $14(15)$ & $8(29)$ & $5(19)$ \\
$\begin{array}{l}\text { Drain with suction } \\
\text { Two drains }\end{array}$ & $4(4)$ & 0 & $5(19)$ \\
Variable & 0 & 0 & $15(58)$ \\
& $31(32)$ & $8(29)$ & $1(4)$ \\
\hline
\end{tabular}

^Apical and basal intercostal drains. staff. Most thoracic surgeons would sometimes perform the procedure themselves $(22,77 \%)$; four of the 29 invariably delegated to a junior and one always performed the pleurodesis himself.

\section{Technique of pleurodesis}

The method used to drain the pleural effusion at pleurodesis varied (table 2). Those using intercostal tube drainage tended to remove the drain either immediately or within 24 hours; only $12(13 \%)$ respiratory physicians, $2(6 \%)$ general physicians, and six $(23 \%)$ thoracic surgeons varied the duration of drainage according to the volume of fluid drained each day.

The first choices of agent for pleurodesis are given in table 3, which shows that thoracic surgeons preferred talc whereas both groups of physicians favoured tetracycline. Fifty three $(55 \%)$ respiratory physicians and 17 $(61 \%)$ general physicians claimed to base their choice of agent on a compromise between efficacy and painlessness whereas most thoracic surgeons $(18,69 \%$ ) gave efficacy as the reason for their selection.

Local anaesthetic was instilled into the pleural space by $50(52 \%)$ respiratory physicians and $18(64 \%)$ general physicians but by only $4(15 \%)$ thoracic surgeons. The latter largely performed pleurodesis under general anaesthetic $(19,73 \%)$ but $4(15 \%)$ did not use general anaesthetic and $3(12 \%)$ varied in this regard.

\section{Opinion of pleurodesis}

Most respondents thought that pleurodesis was uncomfortable but easily manageable with adequate analgesia (table 4). Thoracic surgeons were most confident about the efficacy of the procedure, followed by respiratory physicians; most general physicians believed that it was only sometimes effective (table 4).

\section{Discussion}

Questionnaire surveys are open to bias and the variable response rates from the four groups polled in this study may reflect differing interest in and involvement with pleurodesis. We were particularly surprised by the poor response from general surgeons; breast carcinoma, one of the more common causes of

Table 3 First choice of agent of pleurodesis selected by respiratory physicians, general physicians, and thoracic surgeons

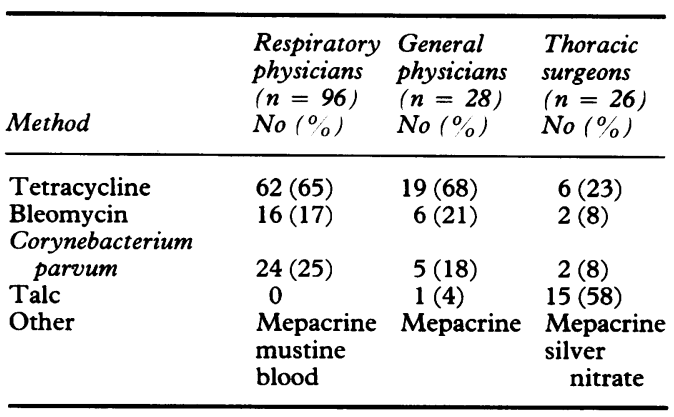


Table 4 Views on pleurodesis held by respiratory physicians, general physicians, and thoracic surgeons

\begin{tabular}{|c|c|c|c|}
\hline Opinion & $\begin{array}{l}\text { Respiratory } \\
\text { physicians } \\
(n=96) \\
\text { No }(\%)\end{array}$ & $\begin{array}{l}\text { General } \\
\text { physicians } \\
(n=28) \\
\text { No }(\%)\end{array}$ & $\begin{array}{l}\text { Thoracic } \\
\text { surgeons } \\
(n=26) \\
\text { No }(\%)\end{array}$ \\
\hline \multicolumn{4}{|l|}{ PAIN } \\
\hline Very painful & $7(7)$ & $5(18)$ & $5(19)$ \\
\hline Manageable & $68(71)$ & $20(71)$ & $16(62)$ \\
\hline \multicolumn{4}{|l|}{ Mild discomfort } \\
\hline only & $21(22)$ & $3(11)$ & $5(19)$ \\
\hline \multicolumn{4}{|l|}{ EFFICACY } \\
\hline Usually effective & $46(48)$ & $2(7)$ & $16(62)$ \\
\hline Sometimes effective & $47(49)$ & $24(86)$ & $6(23)$ \\
\hline Rarely effective & $3(3)$ & $2(7)$ & $3(12)$ \\
\hline Not effective & 0 & 0 & $1(4)$ \\
\hline
\end{tabular}

malignant pleural effusion, ${ }^{i \dddot{3}}$ is frequently managed by general surgeons and we had expected a greater response from this group. In addition, the questionnaire sought the impressions of its respondents rather than audited data and the results must be viewed in the light of this limitation.

Patients with malignant disease and pleural effusion form a very heterogeneous group with respect to symptoms, the improvement expected from removal of pleural fluid, and prognosis. Consequently, the fact that $76 \%$ of the respiratory physicians responding would usually consider pleurodesis in patients with recurrent malignant pleural effusion indicates a very positive approach to these patients. Similarly, although only $30 \%$ of general physicians would usually consider pleurodesis, a further $33 \%$ refer these patients to another specialist, presumably for active management, and only $15 \%$ indicated that their usual practice was thoracocentesis alone. The fact that most thoracic surgeons would perform pleurodesis may simply reflect referral from a physician specifically for this purpose.

The method of performing pleurodesis yielded the greatest variety of responses. The thoracic surgeons' technique is the most consistent and aggressive with the routine use of an intercostal tube drain, usually with suction to maintain the pleural layers in apposition. The physicians' approach is highly variable, ranging from simple needle aspiration of the pleural fluid to "dryness" to tube drainage; some connect suction to the tube drain. There is greater agreement within groups on the agent to be selected but opinion is divided on the need to instil local anaesthetic into the pleural space. Consultant thoracic surgeons perform the procedure much more than the other groups, possibly because it is incorporated into a routine theatre list and may be done in conjunction with thoracoscopy; consultant physicians have little direct contact with the performance of the procedure as the task is usually delegated to a junior doctor. The influence of the rank of the clinician performing the procedure on outcome is not known.

Clear guidance on the best method of performing pleurodesis is not available and published studies have added to the confusion. Talc pleurodesis carried out by a surgeon under general anaesthesia using at least one intercostal tube drain with suction probably has the greatest success rate. ${ }^{11} 12$ Referral to a surgeon, however, may not be geographically conven- ient and such an approach may be appropriate only in relatively fit patients; indeed, this fact may have biased the results of some trials. Studies of "medical" pleurodesis, many of which have been reviewed by Hausheer, ${ }^{3}$ are less easy to interpret for several reasons. Firstly, accounts often relate to the efficacy of a single agent in a heterogeneous group of patients and, as the response of an effusion may be influenced by underlying tumour type, ${ }^{1314}$ comparison of the results of different studies is difficult. This problem is compounded by the differences in the dose of the agent used for the pleurodesis between studies and sometimes even within a study. The technique of pleurodesis varies between needle thoracocentesis followed by injection of the appropriate agent to the use of an aggressive drainage regimen; the method is said to be important to the success of the procedure ${ }^{1516}$ but this aspect has not been subjected to definitive study. Finally, the criteria for assessing response are not always clear or consistent between studies. Even comparing different studies of the efficacy of a particular agent given by an apparently similar technique shows variable results.

A recent editorial review of the management of malignant pleural effusion ${ }^{17}$ concluded by suggesting the need for further research to guide physicians on the most effective method of pleurodesis; our study lends further support to this view. Perhaps the most important issue is whether simple needle aspiration alone before instillation of the agent of pleurodesis will suffice; this is the aspect on which there is least consistency and which most affects the patient. Pleurodesis is a palliative procedure, which is at best uncomfortable for the patient and which must be performed effectively but without undue aggression unless it is of proved value.

This study was supported by an award from the Scottish Branch of the Chest, Heart and Stroke Association.

1 Anderson CB, Philpott GW, Ferguson TB. Treatment of malignant pleural effusions. Cancer 1974;33:916-22.

2 Leff A, Hopewell PC, Costello J. Pleural effusions from malignancy. Ann Intern Med 1978;88:532-7.

3 Hausheer FH, Yarbro JW. Diagnosis and treatment of malignant pleural effusion. Semin Oncol 1985;12:54-75.

4 Fentiman IS, Millis R, Sexton S, Hayward JL. Pleural effusion in breast cancer: a review of 105 cases. Cancer 1981;47:2087-92.

5 Diseases of the Pleura. In: Seaton A, Seaton D, Leitch AG, eds. Crofton and Douglas's Respiratory diseases. Oxford: Blackwell, 1989:1096.

6 Crofton J. Respiratory Disorders. In: Weatherall DJ, Ledingham JGG, Warrell DA, eds. Oxford textbook of medicine. Oxford: Oxford University Press, 1987;15.57, 15.156.

7 Dhillon DP, Spiro SG. Pleural disease: malignant pleural effusions. Br J Hosp. Med 1983; June:506-10.

8 Fentiman IS. Effective treatment of malignant pleural effusions. Br J Hosp Med 1987; May:421-8.

9 British Thoracic Society. Thoracic medical services in Great Britain. London: BTS, 1985.

10 Medical Directory. Edinburgh: Churchill Livingstone, 1986.

1 Fentiman IS, Rubens RD, Hayward JL. Control of pleural effusions in patients with breast cancer. A randomised trial. Cancer 1983;52:737-9.

12 Fentiman IS, Rubens RD, Hayward JL. A comparison of intracavitary talc and tetracycline for the control of pleural intracavitary talc and tetracycline for the control of pleural Oncol 1986;22:1079-81.

13 Ostrowski MJ, Halsall GM. Intracavitary bleomycin in the management of malignant effusions: a multicentre study. Cancer Treat Rep 1982;66:1093-7.

14 Ostrowski MJ. An assessment of the long-term results of controlling the reaccumulation of malignant effusions using intracavity bleomycin. Cancer 1986;57:721-7.

15 Fracchia AA, Knapper WH, Carey JT, Farrow JH. Intrapleural chemotherapy for effusion from metastatic breast carcinoma. Cancer 1970;26:626-9.

16 Good JT, Sahn SA. Intrapleural therapy with tetracycline in malignant pleural effusions. Chest 1978;74:602.

17 Tattersall MHN, Boyer MJ. Management of malignant pleural effusions [editorial]. Thorax 1990;45:81-2. 